\title{
Behavioral outcome among survivors of childhood brain tumor: a case control study
}

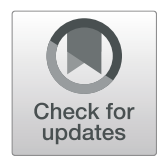

Hamidah Alias ${ }^{1 *}$, Sasirekha Krisnan Morthy ${ }^{4}$, Syed Zulkifli Syed Zakaria', Zulaiha Muda ${ }^{2}$ and Azmi Mohd Tamil ${ }^{3}$

\begin{abstract}
Background: Advances in the treatment of childhood brain tumors have significantly improved survival rates. With improved survival rates, long-term treatment-related toxicities have become important, and the resulting complications can affect patients' emotion and behavior. This study aimed to 1) evaluate behavioral outcomes among survivors of childhood brain tumors, 2) compare behavioral outcomes among survivors of childhood brain tumors with survivors of childhood leukemia and healthy children, and 3) determine any demographic, disease, and/or treatment-related factors that could affect the behavioral outcomes of survivors of childhood brain tumors.

Methods: A comparative cross-sectional study was conducted over a period of 1 year (June 1st, 2018-May 31st, 2019) in two tertiary referral centers in Kuala Lumpur, Malaysia. Thirty-eight survivors of childhood brain tumors aged 6 to 18 years old who had been off-treatment for at least 1 year and were in remission, 38 age- and gendermatched survivors of childhood leukemia who had been off-treatment for at least 1 year and were in remission, and 38 age- and gender-matched unrelated healthy children were recruited. The Child Behaviour Checklist (CBCL) parent report and Youth Self-Report (YSR) questionnaires were used to assess behavioral outcomes.

Results: Survivors of childhood brain tumors showed statistically significantly worse behavioral outcomes than healthy children for social problems and attention problems $(p<0.05$, respectively). A significantly worse outcome was found for "social problems" $(p<0.05)$ in survivors of childhood brain tumors compared to survivors of childhood leukemia. Significant associations were also found between physical disability, visual impairment, education level of survivors, and father's occupation and behavioral outcomes among survivors of childhood brain tumors.
\end{abstract}

Conclusions: Survivors of childhood brain tumors in our center showed poor behavioral outcomes for social problems and attention problems. Thus, effective psychosocial support interventions tailored to individual patients as soon as treatment is completed are important to prevent potentially debilitating emotional problems.

Keywords: Child behavior checklist, Youth self Report, Brain tumor, Survivors, Behavioral outcome

\section{Background}

The incidence of childhood brain tumors has increased by approximately $50 \%$ between the year 1975 and 2000 [1]. Brain tumors are the most common type of solid tumor in children and are a major cause of death among all childhood cancers [2]. The Malaysian National Cancer Registry Report 2007-2011 stated that brain and nervous system tumors are the second most common childhood cancers among Malaysian children aged between 0 and 14 years old. The national incidence of

\footnotetext{
*Correspondence: midalias@ppukm.ukm.edu.my

'Department of Pediatrics, UKM Medical Centre, Faculty of Medicine, The

National University of Malaysia, Cheras, 56000 Kuala Lumpur, Malaysia

Full list of author information is available at the end of the article
}

childhood brain and central nervous system (CNS) tumors is 2 per 100,000 children [3]. Childhood brain tumors are more common in males, although this varies according to histologic type. Benign tumors are generally treated with surgical excision alone, whereas malignant tumors are treated with a combination of chemotherapy and/or radiotherapy postoperatively [4].

Advances in childhood brain tumor treatment have significantly improved survival; the five-year survival rate was almost $75 \%$ with the proportion varying by tumor type [5]. With improved survival rates, attention to disease and/or treatment-related long-term complications such as neurological impairments, cognitive dysfunction

(c) The Author(s). 2020 Open Access This article is distributed under the terms of the Creative Commons Attribution 4.0 International License (http://creativecommons.org/licenses/by/4.0/), which permits unrestricted use, distribution, and 
and growth, and endocrine disturbances has increased [4]. Previous studies reported that survivors of childhood brain tumors were at risk of emotional and behavioral problems such as depression within months of ceasing treatment and returning to the community [4, 6-10]. These behavioral and emotional problems appear to persist into early adulthood and beyond [6].

Childhood and adolescent behavior can be broadly classified as internalizing and externalizing based on their reactions to stressors. Internalizing behaviors are characterized by anxiety, somatization, and/or depression [11]. Externalizing behaviors are characterized by acting out, antisocial behavior, hostility, and aggression [11]. Schultz KA et al. reported that survivors of CNS tumors, leukemia, and neuroblastoma were at risk for poorer behavioral and social outcomes. Survivors of childhood CNS tumors were reported to have significant depression/anxiety, attention deficit, antisocial behavior, and reduced social competence [8]. Internalizing behavior problems were found to be more frequent in survivors, whereas externalizing behaviors were relatively rare based on the parent-reported Child Behaviour Checklist $(\mathrm{CBCL})$ results $[4,9,10]$. Another study reported greater withdrawal and social and attention problems in survivors with a longer time elapsed between diagnosis and assessment $[9,10]$. By contrast, Carpentieri SC et al. and Holmquist LA et al. reported that childhood brain tumor survivors did not have more behavioral problems than survivors of non-CNS tumors $[6,12]$.

Scarce literature reports on associations between behavioral outcomes in survivors of childhood brain tumors and socioeconomic status (SES). Kullgren KA et al. reported that survivors of brain tumors with a lower SES were at a greater risk of behavioral problems [13]. These findings support the importance of developing effective psychosocial support interventions tailored to individual patients that are made accessible from diagnosis and particularly immediately after treatment cessation $[4,7$, 9]. Furthermore, many studies have reported promising outcomes in survivors following individual and group interventions [14-16].

There are few studies on behavioral problems in survivors of childhood cancer in developing countries. We believe it is important to perform a similar study in Malaysia because the results may differ from those reported in developed countries. Factors such as multi-ethnicity and cultural beliefs could contribute to different behavioral problems in survivors. This study aimed to evaluate behavioral outcomes in survivors of childhood brain tumors who were treated at two tertiary referral centers and to compare the behavioral outcomes with survivors of childhood leukemia and unrelated healthy children. We also studied any demographic-related and/or disease- or treatment-related factors that could be associated with behavioral outcomes.

\section{Methods \\ Subjects}

This was a multicenter, comparative cross-sectional study conducted in the Pediatric Hematology and Oncology Unit at the Department of Pediatrics, Universiti Kebangsaan Malaysia Medical Centre and the Hospital Tunku Azizah, Kuala Lumpur over a 1 year period from June 1st, 2018 until May 31st, 2019. All survivors of childhood brain tumors aged 6-18 years old who had completed treatment at least 1 year previously and remained in remission were eligible for this study. Survivors who did not complete treatment, has preexisting behavioral disorders, and parents or patients who did not understand English or Bahasa Malaysia (the national language of Malaysia) were excluded. The two comparative groups consisted of survivors of childhood leukemia and unrelated healthy children, matched for gender and age. Survivors of childhood leukemia with no other illnesses and who had been off-treatment for at least 1 year and remained in remission were recruited. Healthy children not related to the survivors were randomly selected and recruited for the study. All eligible subjects were approached by one investigator. Written informed consent was obtained from the parents prior to subject recruitment. Ethical approval was obtained from the Research Ethics Committee of the Universiti Kebangsaan Malaysia and the Medical Research and Ethics Committee, Ministry of Health prior to the study. Approval for using the original versions of the CBCL and YSR was obtained from the founder, Prof. Dr. Thomas M. Achehbach, Professor of Psychiatry and Psychology, University of Vermont. The questionnaire was translated from the original English version into Bahasa Malaysia and was reviewed by the members of the research team for content validity. It was pilot tested on 30 parents whom were then included in the study. The internal validation of the questionnaire in Bahasa Malaysia was 0.952 (Cronbach's alpha).

\section{Measures \\ $C B C L$ and YSR}

The CBCL parent report is a widely used instrument that assesses social competence and behavioral problems of children 6-18 years of age [17]. The problem scale comprised of 113 questions that fall into three global scales; internalizing, externalizing and total behavioral problems. Eight subscales were assessed: 'anxious/depressed', 'withdrawn/depressed', 'somatic complaints', 'social problems'. 'thought problems', 'attention problems', ' rule-breaking behavior', and 'aggressive behavior'. Parents answered the questions based on their children 
behavior for the past 6 months. Each question was scored on a 3 -point scale $(0=$ not true, $1=$ somewhat or sometimes true, 2 = very true or often true). Raw scores of these measures were transformed to standardized $\mathrm{T}$ scores with higher scores reflecting more behavioral difficulties.

For the 3 global scales; internalizing, externalizing and total behavioral problems, $\mathrm{T}$ scores between 60 and 63 reflect borderline clinical range behavioral problems whereas $\mathrm{T}$ scores more than 63 reflect clinical range behavioral problems. For the 8 subcales, $\mathrm{T}$ scores between 65 and 69 reflect borderline clinical range behavioral problems whereas $\mathrm{T}$ scores more than 69 reflect clinical range behavioral problems. The CBCL has been shown to have strong reliability and validity in clinical and normal population [11].

YSR which was derived from CBCL is a selfadministered form designed for use in children and adolescents aged 11-18 years. The questionnaire consists of 112 items addressing a variety of social competence and behavioral problems. It has 3 global scales with 8 subscales and scoring system similar to CBCL [17].

The parents of patients between 6 and 10 years old completed the CBCL questionnaire. Conversely, for patients between 11 and 18 years, both the parents and the patients completed the CBCL and YSR questionnaires, respectively.

Statistical analysis All statistical calculations were conducted using the Statistical Product for the Service Solution program version 20. Since the data were not normally distributed, non-parametric tests were used for the statistical analyses. The Kruskal-Wallis test was conducted to evaluate the differences in behavioral outcomes among the three groups of survivors. When indicated, post hoc analyses with the Mann-Whitney U test were then conducted to perform pairwise comparisons. To determine any demographic, disease, and/or treatment-related factors that could affect behavioral outcomes, the continuous data were analyzed using the Mann-Whitney $U$ test for two comparison groups, whereas the Kruskal-Wallis test was used for more than two comparison groups. Spearman's rank order correlation was used to analyze the correlation between $\mathrm{CBCL}$ parental reports and the YSR. Non-normally distributed continuous data were presented as the median and centile. Categorical data were analyzed using the chi-square test and presented as the frequency and percentage.

\section{Results}

\section{Subjects}

A total of 72 survivors of childhood brain tumors who were still being followed-up were identified from the database. Thirty-four of the 72 survivors were excluded because they did not fulfill the inclusion criteria for the following reasons: younger than 6 years old $(n=6)$, older than 18 years old $(n=11)$, did not complete treatment $(n=1)$, less than 1 year removed from treatment $(n=6)$, on palliative chemotherapy $(n=3)$, language barrier $(n=$ $1)$, did not provide consent $(n=1)$, uncontactable $(n=3)$, and did not return the questionnaire $(n=2)$. Thirtyeight survivors of childhood brain tumors, 38 age- and gender-matched childhood leukemia survivors, and 38 age- and gender-matched unrelated healthy children were recruited for this study. The demographic and clinical characteristics of the survivors of childhood brain tumors are shown in Tables 1 and 2. All relapsed patients were treated. Thirty-two of the 38 survivors had received radiotherapy as a part of treatment. All survivors of childhood leukemia had acute lymphoblastic leukemia (ALL) except one who had acute myeloid leukemia. There were no significant differences in the demographic variables between the survivors of childhood brain tumors and the survivors of childhood leukemia and healthy children except for ethnicity, number of siblings, survivors' education, and mothers' occupation; half of the survivors of childhood brain tumors had mothers who were housewives compared to 37 and $13 \%$ of childhood leukemia survivors and healthy children, respectively. Thirteen of the survivors of childhood brain tumors attended special education whereas none of the childhood leukemia survivors and healthy children did so.

\section{$\mathrm{CBCL}$ and YSR}

The survivors of childhood brain tumors showed statistically significantly worse behavioral outcomes for social problems $(p=0.006)$ and attention problems $(p=0.007)$ compared to age- and gender-matched healthy children. When compared to survivors of childhood leukemia, childhood brain tumor survivors showed statistically significantly worse behavioral outcomes for social problems $(p=0.022)$. There were no statistically significant differences in the behavioral outcomes of survivors of childhood brain tumors compared to the two comparison groups on the three global scales (internalizing, externalizing, and total behavioral problems) and other subscales (anxious, withdrawn/depressed, somatic complaints, thought problems, rule breaking, and aggressive behavior) (Table 3).

Survivors with either physical, hearing, and/or visual disabilities had poor total behavioral problems $(p=$ $0.015)$, externalizing problems $(p=0.006)$, social problems $(p=0.005)$, rule breaking behavior $(p=0.025)$, and aggressive behavior $(p=0.004)$. In the subgroup analyses, survivors of childhood brain tumors with physical disabilities showed statistically significantly worse outcomes for total behavioral problems $(p=0.036)$, social problems 
Table 1 Demographic characteristic of survivors of childhood brain tumor, survivors of childhood leukemia and healthy controls

\begin{tabular}{|c|c|c|c|c|}
\hline Characteristic & $\begin{array}{l}\text { Childhood brain } \\
\text { tumor survivors } \\
N(\%)\end{array}$ & $\begin{array}{l}\text { Childhood } \\
\text { leukemia } \\
\text { survivors } \\
\text { N (\%) }\end{array}$ & $\begin{array}{l}\text { Healthy } \\
\text { control } \\
N(\%)\end{array}$ & $p$-value \\
\hline
\end{tabular}

Age at study entry, years

$\begin{array}{lllll}6-10.9 & 15(39.5) & 16(42.1) & 16(42.1) & 1.000 \\ 11-18.9 & 23(60.5) & 22(57.9) & 22(57.9) & \\ \text { Gender } & & & & \\ \text { Male } & 24(63.2) & 24(63.2) & 24(63.2) & 1.000 \\ \text { Female } & 14(36.8) & 14(36.8) & 14(36.8) & \end{array}$

Ethnicity

Malay

$\begin{array}{ll}\text { Chinese } & 6(15.8) \\ \text { Indian } & 1(2.6) \\ \text { Others } & 0(0) \\ \text { ducation } & \end{array}$

Education

Primary $\quad 15(39.5)$

Secondary $\quad 9(23.7)$

Tertiary $0(0)$

Special education $13(34.2)$

None $\quad 1$ (2.6)

Parents marital status

$\begin{array}{ll}\text { Married } & 37(97.4) \\ \text { Single parent } & 1(2.6)\end{array}$

Father's education level

No formal education 1 (2.6)

$\begin{array}{ll}\text { Primary } & 6(15.8) \\ \text { Secondary } & 20(52.6)\end{array}$

Tertiary $\quad 11(28.9)$

Father's occupation

$\begin{array}{ll}\text { Office work } & 7(18.4) \\ \text { Field work } & 8(21.1) \\ \text { Professional } & 4(10.5) \\ \text { Others } & 16(42.1) \\ \text { Not working } & 3(7.9)\end{array}$

Mother's education level

$\begin{array}{lllll}\text { No formal education } & 1(2.6) & 0(0) & 0(0) & 0.501 \\ \text { Primary } & 6(15.8) & 3(8.1) & 5(13.2) & \\ \text { Secondary } & 18(47.4) & 21(56.8) & 15(39.5) & \\ \text { Tertiary } & 13(34.2) & 13(35.1) & 18(47.4) & \\ \text { Mother's occupation } & & & & \\ \text { Office work } & 8(21.1) & 6(16.2) & 7(18.4) & 0.023 \\ \text { Field work } & 2(5.3) & 1(2.7) & 2(5.3) & \\ \text { Professional } & 5(13.2) & 9(24.3) & 10(26.3) & \\ \text { Others } & 4(10.5) & 7(18.9) & 14(36.8) & \end{array}$

Table 1 Demographic characteristic of survivors of childhood brain tumor, survivors of childhood leukemia and healthy controls (Continued)

\begin{tabular}{|c|c|c|c|c|}
\hline Characteristic & $\begin{array}{l}\text { Childhood brain } \\
\text { tumor survivors } \\
N(\%)\end{array}$ & $\begin{array}{l}\text { Childhood } \\
\text { leukemia } \\
\text { survivors } \\
\mathrm{N}(\%)\end{array}$ & $\begin{array}{l}\text { Healthy } \\
\text { control } \\
\text { N (\%) }\end{array}$ & $p$-value \\
\hline Housewife & $19(50)$ & $14(37.8)$ & $5(13.2)$ & \\
\hline \multicolumn{5}{|c|}{ Family monthly income } \\
\hline$<$ MYR 1000 & $2(5.3)$ & $0(0)$ & $1(2.6)$ & \\
\hline MYR 1001-3000 & $14(36.8)$ & $10(26.3)$ & $8(21.1)$ & 0.328 \\
\hline MYR 3001-5000 & $8(21.1)$ & $17(44.7)$ & $13(34.2)$ & \\
\hline MYR 5001-7000 & $4(10.5)$ & $2(5.3)$ & $2(5.3)$ & \\
\hline MYR 7001-9000 & $3(7.9)$ & $3(7.9)$ & $2(5.3)$ & \\
\hline$>$ MYR 9000 & $7(18.4)$ & $6(15.8)$ & $12(31.6)$ & \\
\hline \multicolumn{5}{|l|}{ Number of siblings } \\
\hline None & $5(13.2)$ & $4(10.5)$ & $1(2.6)$ & $<0.005$ \\
\hline 1 & $0(0)$ & $1(2.6)$ & $13(34.2)$ & \\
\hline $2-5$ & $22(57.9)$ & $32(84.2)$ & $24(63.2)$ & \\
\hline$>5$ & $11(28.9)$ & $1(2.6)$ & $0(0)$ & \\
\hline \multicolumn{5}{|c|}{ Siblings with chronic illness/disability } \\
\hline Yes & $1(2.6)$ & $0(0)$ & $0(0)$ & 0.330 \\
\hline No & $37(97.4)$ & $38(100)$ & $38(100)$ & \\
\hline
\end{tabular}

$N$ number, MYR Ringgit Malaysia; analyses using chi square test

$(p=0.001)$, and attention problems $(p=0.028)$. Survivors with visual impairment showed poor outcomes in total behavioral problems $(p=0.019)$, internalizing problems $(p=0.036)$, and social problems $(p=0.010)$. There was no statistically significant association between hearing impairment and behavioral outcomes in the survivors (Table 4). Statistically significantly worse behavioral outcomes for social problems $(p=0.001)$ were observed in survivors who attended special education compared to those in primary education (Table 5).

Fathers' occupation was found to be associated with the $\mathrm{CBCL}$ parental reports. However, the results were too variable. Statistically significantly worse behavioral outcomes for thought problems $(p=0.026)$ and rule breaking behavior $(p=0.035)$ were observed in survivors whose fathers worked in the fields compared to those whose fathers performed office work. Upon comparison with the fathers who were professionals, survivors with fathers who worked in the fields showed statistically significantly worse outcomes for attention problems $(p=0.010)$ and rule breaking behavior $(p=0.008)$. Conversely, compared to survivors whose fathers were in the "other" occupation group, survivors with fathers who worked in the fields showed statistically significant problems in rule breaking behavior $(p=0.015)$ (Table 6). Significant findings were also observed in survivors whose fathers did not work compared to fathers who were 
Table 2 Clinical characteristics of survivors of childhood brain tumor

\begin{tabular}{|c|c|}
\hline Characteristics & Mean $( \pm$ \\
\hline Age at diagnosis, year & $7.2(3.6)$ \\
\hline Age at study entry, year & $12.5(3.7)$ \\
\hline \multirow[t]{2}{*}{ Time from end of treatment to study, year } & $5.5(3.9)$ \\
\hline & N (\%) \\
\hline \multicolumn{2}{|l|}{ Pathology } \\
\hline Medulloblastoma & $14(36.8)$ \\
\hline Germ Cell Tumor & $10(26.3)$ \\
\hline Craniopharygioma & $5(13.2)$ \\
\hline Glioma & $2(5.3)$ \\
\hline PNET & $2(5.3)$ \\
\hline Others & $5(13.2)$ \\
\hline \multicolumn{2}{|l|}{ Tumour location } \\
\hline Supratentorial & $21(55.3)$ \\
\hline Infratentorial & $17(44.7)$ \\
\hline \multicolumn{2}{|l|}{ Treatment } \\
\hline Tumor excision only & $2(5.3)$ \\
\hline Tumor excision + radiotherapy & $6(15.8)$ \\
\hline Tumor excision + radiotherapy + chemotherapy & $20(52.6)$ \\
\hline Tumor excision + chemotherapy & $3(7.9)$ \\
\hline Biopsy + radiotherapy + chemotherapy & $2(5.3)$ \\
\hline Biopsy + radiotherapy & $2(5.3)$ \\
\hline Chemotherapy + radiotherapy & $2(5.3)$ \\
\hline Radiotherapy only & $1(0.9)$ \\
\hline Complications from disease and treatment & $N(\%)$ \\
\hline \multicolumn{2}{|l|}{ Hydrocephalus } \\
\hline Yes & $24(63.2)$ \\
\hline No & $14(36.8)$ \\
\hline \multicolumn{2}{|l|}{ Shunt } \\
\hline Yes & $23(60.5)$ \\
\hline No & $15(39.5)$ \\
\hline \multicolumn{2}{|l|}{ Intracranial infection after diagnosis (ventriculitis) } \\
\hline Yes & $2(5.3)$ \\
\hline No & $36(94.7)$ \\
\hline \multicolumn{2}{|l|}{ Relapse } \\
\hline Yes & $6(15.8)$ \\
\hline No & $32(84.2)$ \\
\hline \multicolumn{2}{|l|}{ Disability (Physical, Hearing and Visual) } \\
\hline Yes & $28(73.7)$ \\
\hline No & $10(26.3)$ \\
\hline \multicolumn{2}{|l|}{ Type of disability } \\
\hline Physical impairment & $13(34.2)$ \\
\hline Hearing impairment & $7(18.4)$ \\
\hline Visual impairment & $25(65.8)$ \\
\hline
\end{tabular}

Table 2 Clinical characteristics of survivors of childhood brain tumor (Continued)

\begin{tabular}{ll}
\hline Characteristics & Mean $( \pm$ SD) \\
\hline Endocrinopathy & \\
Yes & $19(50)$ \\
No & $19(50)$ \\
\hline
\end{tabular}

professionals for total behavioral problems $(p=0.032)$, attention problems $(p=0.031)$, and rule breaking behaviors $(p=0.026)$. Compared to survivors of fathers in the "other" occupation group, survivors of fathers who did not work also demonstrated significantly worse behavioral outcomes for total behavioral problems $(p=0.010)$, thought problems $(p=0.014)$, and attention problems $(p=0.016)$. Isolated poor attention problems $(p=0.013)$ were observed in survivors whose fathers performed office work compared to fathers who were professionals (Table 6). Age at diagnosis, gender, ethnicity, parents' marital status, parents' education level, mothers' occupation, total family income, and number of siblings were not found to be associated with poor behavioral outcomes in our study. Similarly, tumor location, mode of treatment, presence of hydrocephalus, presence of intracranial shunt, history of intracranial infection (ventriculitis) after diagnosis, disease relapse, and presence of endocrinopathy were not found to influence behavioral outcomes in childhood brain tumor survivors.

We found strong correlation between CBCL parent reports and YSR in internalizing problems (Spearman's coefficient $=0.701, p$ value $=0.001)$ and total behavioral problems (Spearman's coefficient $=0.629, p$ value $=$ 0.004). Moderate correlation was found between CBCL parent reports and YSR in externalizing problems (Spearman's coefficient $=0.419, p$ value $=0.074$ ).

\section{Discussion}

In this study, we found that survivors of childhood brain tumors have more social and attention problems compared to unrelated healthy children and more social problems compared to survivors of childhood leukemia. Social problems among survivors of childhood brain tumors have also been documented in previous studies $[6$, $8-10,14,18,19]$. A few factors may contribute to these findings. Parents who are overprotective may limit the involvement of survivors in family or social activities due to fear of rejection. This could prevent interpersonal skills development and lead to decreased self-confidence and worsened social isolation among survivors [20]. Furthermore, post-traumatic syndrome disorder, which may have occurred during the diagnosis of the brain tumor, and the experience of stress or a traumatic condition during treatment, may continue to affect the survivor for 
Table 3 CBCL scores of survivors of childhood brain tumor vs survivors of childhood leukemia vs healthy controls

\begin{tabular}{lllc}
\hline Scales & $\begin{array}{l}\text { Childhood brain tumor survivors } \\
(n=38) \text { Median (IQR) }\end{array}$ & $\begin{array}{l}\text { Childhood leukemia survivors } \\
(n=38) \text { Median (IQR) }\end{array}$ & $\begin{array}{l}\text { Healthy children } \\
(n=38) \text { Median (IQR) }\end{array}$ \\
\hline $\begin{array}{l}\text { Main scales } \\
\text { Internalizing score }\end{array}$ & $57.5(50.0-65.5)$ & $53.0(46.8-63.5)$ & $53.0(41.0-59.3)$ \\
Externalizing score & $52.5(47.0-58.3)$ & $51.0(44.0-59.0)$ & $51.5(42.5-57.5)$ \\
Total score & $56.0(49.8-62.0)$ & $53.0(44.8-61.0)$ & $52.0(41.8-57.3)$ \\
Subscales & & & 0.061 \\
Anxious & $52.0(50.8-62.3)$ & $52.0(51.0-62.3)$ & $51.5(50.0-60.0)$ \\
Withdrawn/depressed & $56.5(52.0-63.0)$ & $52.5(50.0-63.0)$ & $53.5(50.0-58.5)$ \\
Somatic complaints & $56.5(51.0-70.0)$ & $53.0(50.0-58.8)$ & $53.0(50.0-61.8)$ \\
Social problems & $58.5(53.0-66.0)$ & $53.5(51.0-58.5)$ & $52.5(50.0-58.5)$ \\
Thought problems & $54.0(50.0-61.0)$ & $52.5(50.0-58.0)$ & $50.0(50.0-56.8)$ \\
Attention problems & $57.0(52.0-62.5)$ & $53.0(51.8-57.0)$ & $54.5(51.0-57.0$ \\
Rule breaking behaviour & $52.0(51.0-54.0)$ & $51.0(50.0-55.5)$ & 0.175 \\
Aggressive behavior & $53.5(50.8-57.3)$ & $53.5(50.0-61.0)$ & $\mathbf{0 . 0 1 2}$ \\
\hline
\end{tabular}

$N$ number, IQR interquartile range (25th centile -75 th centile); analysis using Kruskal-Wallis test

*significant difference is between brain tumor survivors and healthy children and leukemia survivors (Mann-Whitney U test)

** significant difference is between brain tumor survivors and healthy children (Mann-Whitney $U$ test)

statistically significant with $p$-value $<0.05$

some time. Consequently, the survivors could experience low self-esteem and poor self-concept [21].

Demographic, disease, and/or treatment-related factors can influence behavioral outcomes in survivors of childhood brain tumors. We found that survivors of childhood brain tumors with a combination of physical, visual, and/or hearing impairments or any one of these components reported poor behavioral outcomes. Survivors with a physical disability were found to have significant total behavior, social, and attention problems. Survivors with a visual impairment had significant total behavior, internalizing, and social problems. A spectrum of motor deficit could occur in survivors of brain tumors including hemiplegia, leg muscle weakness, spasticity, and abnormal gait due to the tumor itself or the corresponding treatment. Motor deficits contribute to declines in functional status and health-related quality of life in survivors [22]. Decreased function in gross motor skills, particularly balancing and running speed, has been observed in posterior fossa tumor survivors [23]. Survivors of childhood brain tumors were also found to have reduced muscle strength and fitness similar to those found in individuals over 60 years old [24]. All this could lead to limitations in physical performance and restricted participation in home, social, and educational activities, eventually causing poor social functioning, social isolation, and low self-esteem [24].

Carpentieri SC et al. reported that tumor location was a risk factor for behavioral problems among survivors of childhood brain tumors however, Poggi Get et al. found no significant differences between CBCL scores and site or type of tumor $[10,12]$. Age at the time of diagnosis and age when chemotherapy and radiation therapy were commenced were not reported to be significantly related to internalizing or externalizing maladaptive behaviors $[6,9,13]$. Holmquist LA et al. reported that vincristine, cytoxan, cisplatinum, and/or etoposide drugs were associated with late onset emotional and behavioral problems with internalizing behaviors being the most prevalent and significant in survivors of brain tumors [6]. Although radiation therapy has been frequently associated with poorer behavioral and social outcomes in survivors of childhood brain tumors, some researchers reported that the type and total dose of radiation therapy and extension of the radiotherapy field did not have any impact on parents' ratings of behavioral problems $[6,9$, 10]. Likewise, the magnitude of tumor resection and insertion of a shunt for hydrocephalus were not associated with childhood brain tumor survivors' behavior $[6,9]$. Nevertheless, most previous studies assessed heterogenous groups of survivors of childhood brain tumors, which may obscure patterns in behavioral outcomes related to specific locations or treatment modalities. Poretti A et al. studied outcomes in craniopharyngioma survivors and reported that both YSR and parent-rated $\mathrm{CBCL}$ results showed clinically significant scores in total and internalizing problems with social problems as the most affected subscale [25]. Dolson EP et al. found that craniopharyngioma survivors who had extensive tumor resection manifested baseline internalizing and externalizing problems before conformal irradiation [26]. In this subgroup of survivors, the presence of cerebrospinal fluid shunting, Ommaya reservoir for cyst drainage, diabetes insipidus, and lower pre-irradiation 


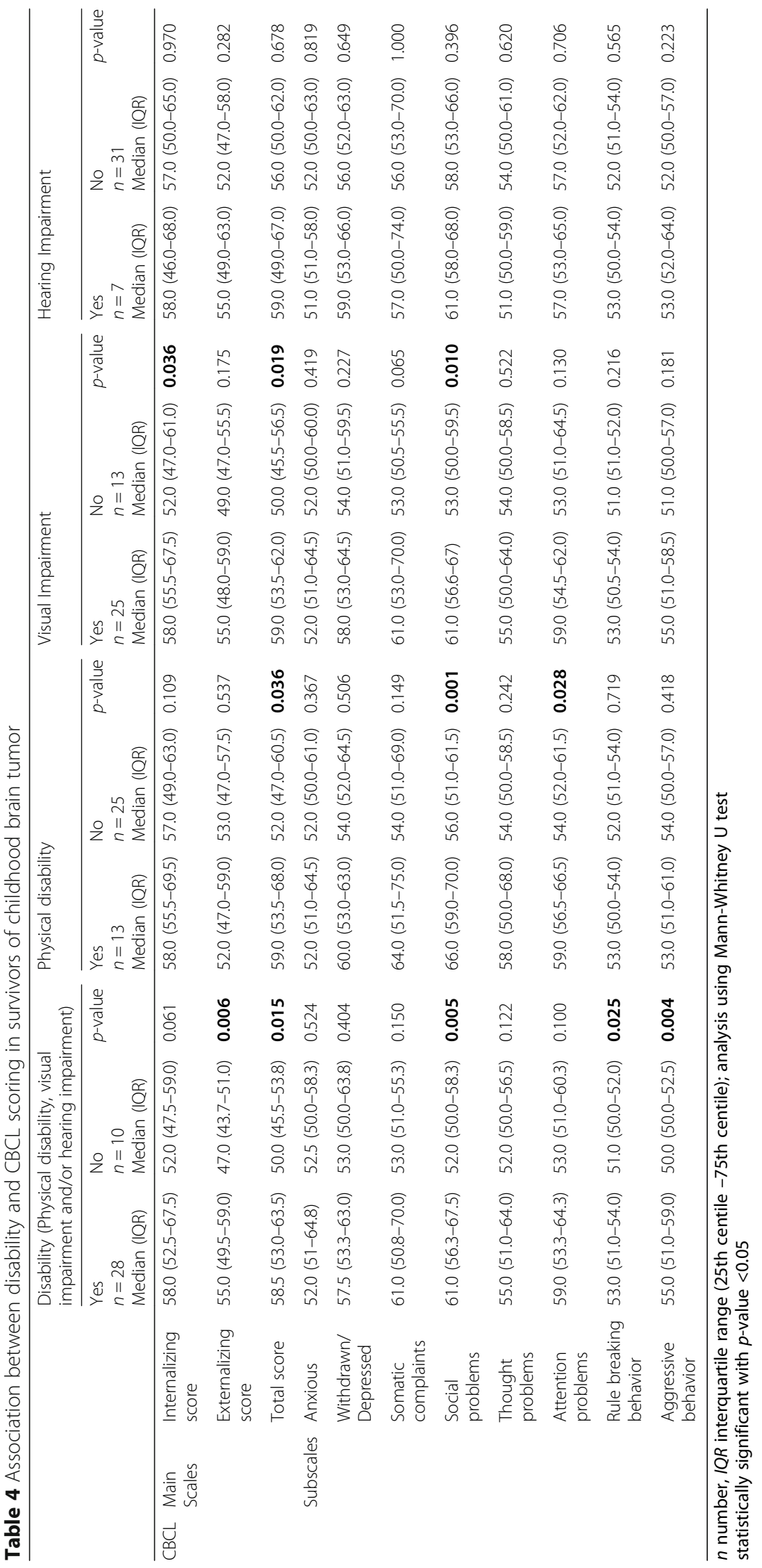


Table 5 Association between survivors' of childhood brain tumor education level and CBCL scores

\begin{tabular}{|c|c|c|c|c|c|c|c|}
\hline \multicolumn{3}{|c|}{ Survivors' education level } & \multirow{2}{*}{$\begin{array}{l}\text { Primary education } \\
n=15 \text { Median (IQR) } \\
54.0(48.0-65.0)\end{array}$} & \multirow{2}{*}{$\begin{array}{l}\text { Secondary education } \\
n=9 \text { Median (IQR) } \\
58.0(54.5-60.5)\end{array}$} & \multirow{2}{*}{$\begin{array}{l}\text { No formal } \\
\text { education } \\
n=1\end{array}$} & \multirow{2}{*}{$\begin{array}{l}\text { Special education } \\
n=13 \text { Median (IQR) } \\
58.0(51.0-69.0)\end{array}$} & \multirow{2}{*}{$\begin{array}{l}p \text {-value } \\
0.242\end{array}$} \\
\hline $\mathrm{CBCL}$ & Main Scales & Internalizing score & & & & & \\
\hline & & Externalizing score & $51.0(47.0-56.0)$ & $52.0(43.5-58.0)$ & 44.0 & $59.0(49.5-59.5)$ & 0.159 \\
\hline & & Total score & $53.0(46.0-59.0)$ & $56.0(49.5-60.0)$ & 62.0 & $59.0(52.0-68.0)$ & 0.150 \\
\hline & Subscales & Anxious & $52.0(50.0-62.0)$ & $52.0(50.5-59.5)$ & 57.0 & $55.0(51.0-64.5)$ & 0.783 \\
\hline & & Withdrawn/Depressed & $54.0(50.0-66.0)$ & $54.0(52.5-61.5)$ & 63.0 & $58.0(55.0-61.0)$ & 0.596 \\
\hline & & Somatic complaints & $55.0(51.0-61.0)$ & $64.0(53.0-70.0)$ & 78.0 & $61.0(50.0-74.0)$ & 0.233 \\
\hline & & Social problems & $55.0(50.0-58.0)$ & $56.0(52.0-56.0)$ & 69.0 & $63.0(60.0-69.0)$ & $0.006^{*}$ \\
\hline & & Thought problems & $54.0(50.0-58.0)$ & $55.0(50.5-65.0)$ & 50.0 & $55.0(50.5-67.0)$ & 0.416 \\
\hline & & Attention problems & $55.0(52.0-61.0)$ & $53.0(52.0-59.0)$ & 59.0 & $65.0(58.0-67.0)$ & 0.050 \\
\hline & & Rule breaking behavior & $52.0(51.0-53.0)$ & $51.0(50.0-54.0)$ & 50.0 & $53.0(50.5-54.0)$ & 0.537 \\
\hline & & Aggressive behavior & $51.0(50.0-55.0)$ & $52.0(50.0-58.0)$ & 50.0 & $57.0(51.5-63.0)$ & 0.072 \\
\hline
\end{tabular}

$\mathrm{n}$ : number, value presented as median (25th centile - 75th centile), analysis using Kruskal-Wallis test

*significant difference is between primary education and special education (Mann-Whitney $U$ test)

statistically significant with $p$-value $<0.05$

growth hormone levels were predictors for worse behavioral outcomes after conformal radiation therapy [26]. In another study, patients with high-risk treatment, those with posterior fossa syndrome, and females were found to have greater withdrawn/ depressive and social problems [27]. We did not find any significant association between behavioral outcome and location of tumour, mode of treatment, presence of hydrocephalus, presence of intracranial shunt, history of intracranial infection after diagnosis, disease relapse and presence of endocrinopathy in our study population.

We found an association between survivors of childhood brain tumors and their education level. Those survivors who attended special education were found to have more social problems compared to survivors in

Table 6 Association between father's occupation and CBCL scores of survivors of childhood brain tumor

\begin{tabular}{|c|c|c|c|c|c|c|}
\hline Father's occupation & $\begin{array}{l}\text { Not working } \\
n=3 \text { Median (IQR) }\end{array}$ & $\begin{array}{l}\text { Office work } \\
n=7 \text { Median (IQR) }\end{array}$ & $\begin{array}{l}\text { Field work } \\
n=8 \text { Median (IQR) }\end{array}$ & $\begin{array}{l}\text { Professionals } \\
n=4 \text { Median (IQR) }\end{array}$ & $\begin{array}{l}\text { Others } \\
n=16 \text { Median (IQR) }\end{array}$ & $p$-value \\
\hline \multicolumn{7}{|l|}{ Main Scale } \\
\hline Internalizing score & $68.0(59.0-68.0)$ & $67.0(50.0-70.0)$ & $61.0(54.8-65.0)$ & $54.5(46.5-67.8)$ & $54.0(48.5-58.0)$ & 0.077 \\
\hline Externalizing score & $58.0(55.0-58.0)$ & $56.0(44.0-59.0)$ & $53.0(51.0-61.5)$ & $47.5(44.0-49.5)$ & $50.5(46.3-57.5)$ & 0.122 \\
\hline Total score & $68.0(61.0-68.0)$ & $59.0(53.0-65.0)$ & $60.0(53.8-65.8)$ & $50.5(46.8-58.0)$ & $51.0(48.3-58.8)$ & $0.029^{*}$ \\
\hline \multicolumn{7}{|l|}{ Subscales } \\
\hline Anxious & $56.0(55.0-56.0)$ & $57.0(50.0-66.0)$ & $59.0(52.0-63.5)$ & $53.0(50.8-70.3)$ & $51.0(50.0-52.0)$ & 0.124 \\
\hline Withdrawn/depressed & $60.0(60.0-60.0)$ & $63.0(54.0-68.0)$ & $55.0(50.0-61.3)$ & $52.5(50.5-60.5)$ & $56.5(52.3-62.3)$ & 0.341 \\
\hline Somatic complaints & $74.0(50.0-74.4)$ & $61.0(53.0-76.0)$ & $57.5(53.0-70.0)$ & $59.5(51.3-68.5)$ & $53.0(50.3-63.3)$ & 0.438 \\
\hline Social problems & $68.0(66.0-68.0)$ & $62.0(53.0-69.0)$ & $60.5(55.5-67.5)$ & $53.0(51.5-65.8)$ & $58.0(51.5-60.8)$ & 0.132 \\
\hline Thought problems & $66.0(64.0-66.0)$ & $50.0(50.0-51.0)$ & $57.0(52.8-60.3)$ & $56.0(50.3-64.8)$ & $54.0(50.0-57.3)$ & $0.038^{* *}$ \\
\hline Attention problems & $66.0(62.0-66.0)$ & $59.0(53.0-62.0)$ & $61.0(55.3-70.0)$ & $51.5(51.0-52.0)$ & $57.0(52.3-60.5)$ & $0.011^{\S}$ \\
\hline Rule breaking behavior & $54.0(54.0-54.0)$ & $51.0(50.0-53.0)$ & $53.5(53.0-54.8)$ & $51.0(50.3-51.8)$ & $51.0(50.0-53.4)$ & $0.019^{9}$ \\
\hline Aggressive behavior & $57.0(56.0-57.0)$ & $55.0(50.0-61.0)$ & $53.0(51.0-62.5)$ & $50.5(50.0-51.0)$ & $53.5(50.0-57.8)$ & 0.174 \\
\hline
\end{tabular}

$\mathrm{n}$ : number, value presented as median (25th centile -75 th centile), analyses using Kruskal-Wallis test

Mann-Whitney $U$ test

* Significant difference is between professionals and not working fathers and between others and not working fathers

** Significant difference is between office workers and field workers and between others and not working fathers

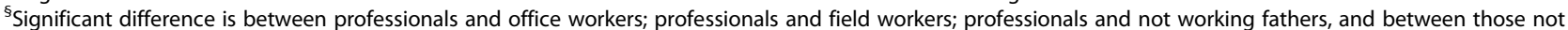
working and others

"Significant difference is between field workers and office workers; between professionals and field workers; between field workers and others and between professionals and not working fathers

statistically significant with $p$-value $<0.05$ 
primary education. This is explained by the intellectual, physical, visual, or hearing impairments in the survivors following the treatment received. In general, survivors whose fathers worked in the fields and those who did not work showed poor behavioral outcomes. Fathers who worked in the fields and were unemployed may have a lower education level and might have difficulty in understanding the disease, be anxious, or lack a coping mechanism.

We did not identify significant differences in behavioral problems between survivors of childhood brain tumors and leukemia survivors on the global scales and most of the subscales. This supports the findings of Carpentieri SC et al. and Holmquist LA et al. who reported that survivors of childhood brain tumors did not have more behavioral problems than survivors of nonCNS tumors $[6,12]$. However, we must cautiously interpret these findings because parents may underreport behavioral problems in their children. Some parents may be overprotective of their children who survived a brain tumor because they perceive them as very vulnerable. Overprotective parents and their difficulties with encouraging autonomy in survivors of brain tumors have been documented previously [28]. Nevertheless, the lack of knowledge on long-term emotional and behavioral problems and its urgency from the parents' perspective may also contribute to underreporting [28]. Thus, survivors of childhood brain tumors should be regularly assessed for possible emotional and behavioral problems.

\section{Strengths and limitations}

Many previous studies compared the findings on survivors of brain tumors with normative values but rarely used a comparison group. A shortcoming of only comparing to normative data is overestimating the rate of behavioral problems in survivors. Our study recruited two comparison groups; thus, the results are expected to have a higher validity. However, this study has a few limitations that should be considered when interpreting the results. The study population was small, and the participants had heterogenous diagnoses. Given the small prevalence of childhood brain tumors, this is a challenge despite the involvement of two centers in this study. A nationwide collaboration would help minimize this limitation. Furthermore, a longitudinal study would be more predictive and accurate in revealing behavioral changes that occur over time, particularly any emotional stress patterns in survivors.

\section{Conclusions}

Our study findings show that survivors of childhood brain tumors exhibited significant behavioral problems, specifically social and attention problems. Physical disabilities, visual impairment, survivor's education level, and father's occupation were associated with poor behavioral outcomes.

\section{Abbreviations \\ ALL: Acute lymphoblastic leukemia; CBCL: Child Behavior Checklist; CNS: Central nervous system; SES: Socioeconomic status; YSR: Youth Self- Report}

\section{Acknowledgements}

Not applicable.

\section{Authors' contributions}

HA and SKM worked on concept and design of the study, data collection, statistical analyses with guidance from SZSZ and AMT, and drafted the manuscript. ZM was involved in the data collection. All authors were involved in the interpretation of data and critically revising the manuscript and approving the final version. All authors read and approved the final manuscript.

\section{Funding}

This study was approved by the Ethics without funding.

Availability of data and materials

The datasets used and/or analyzed during the current study are available from the corresponding author on reasonable request.

Ethics approval and consent to participate

This study was approved by the Universiti Kebangsaan Malaysia Medical Centre Ethics and Research Committee and MREC without research funding (research code: UKM PPI/111/8/JEP-2018-494 and MREC Research ID 39274).

\section{Consent for publication}

Parental written consent has been obtained allowing inclusion of material pertaining to the patient. The patient's parents were informed that no identifying information will be published and this has been acknowledged by them.

\section{Competing interests}

The authors declare that they have no competing interests.

\section{Author details}

${ }^{1}$ Department of Pediatrics, UKM Medical Centre, Faculty of Medicine, The National University of Malaysia, Cheras, 56000 Kuala Lumpur, Malaysia. ${ }^{2}$ Institut Pediatrik, General Hospital Kuala Lumpur, The National University of Malaysia, Kuala Lumpur, Malaysia. ${ }^{3}$ Department of Public Health, Faculty of Medicine, The National University of Malaysia, Kuala Lumpur, Malaysia.

${ }^{4}$ Hospital Tunku Azizah, Kuala Lumpur, Malaysia.

Received: 3 September 2019 Accepted: 29 January 2020

Published online: 05 February 2020

\section{References}

1. Onal C. Epidemiology of Paediatric brain Tumours. Med Sci. 2012;1 (1):65-76

2. Crawford J. Childhood brain tumors. Pediatr Rev. 2013;34:63-78.

3. Azizah AM, Nor Saleha IT, Noor Hashimah A, Asmah ZA, Mastulu W. Malaysian Cancer Registry Report 2007-2011. Putrajaya: National Cancer Institute, Ministry of Health; 2016. http://nci.moh.gov.my.

4. Gerber NU, Zehnder D, Zuzak TJ, Poretti A, Boltshauser E, Grotzer MA. Outcome in children with brain tumours diagnosed in the first year of life: long term complications and quality of life. Arch Dis Child. 2008;93:582-9.

5. Noone AM, Howlader N, Krapcho M, Miller D, Brest A, Yu M, et al. (eds). SEER Cancer Statistics Review, 1975-2015. Bethesda: National Cancer Institute. https://seer.cancer.gov/csr/1975_2015/, based on November 2017 SEER data submission, posted to the SEER web site, April 2018.

6. Holmquist LA, Scott J. Treatment, age and time-related predictors of behavioural outcome in pediatric brain tumor survivors. J Child Psychol Med Settings. 2002;9(4):315-21

7. Schulte F, Barrera M. Social competence in childhood brain tumour survivors: a comprehensive review. Support Care Cancer. 2010;18:1499-513.

8. Schultz KA, Ness KK, Whitton J, Recklitis C, Zebrack B, Robison LL, et al. Behavioural and social outcomes in adolescent survivors of childhood 
cancer: a report from the childhood cancer survivor study. J Clin Oncol. 2007;25(24):3649-59.

9. Mabbott DJ, Spiegler BJ, Greenberg ML, Rutka JT, Hyder DJ, Bouffet E. Serial evaluation of academic and behavioural outcome after treatment with cranial radiation in childhood. J Clin Oncol. 2005;23(10):2256-63.

10. Poggi G, Liscio M, Galbiati S, Adduci A, Massimino M, Gandola L, et al. Brain tumours in children and adolescents: cognitive and psychological disorders at different ages. Psychooncology. 2005;14(5):386-95.

11. American Psychological Association. APA Dictionary of Psychology [Internet]. Available from: https://dictionary.apa.org/externalizinginternalizing. Accessed 25 Feb 2019.

12. Carpentieri SC, Mulhern RK, Douglas S, Hanna S, Fairclough DL. Behavioural resiliency among children surviving brain tumours: a longitudinal study. J Clin Child Psychol. 1993;22(2):236-46.

13. Kullgren KA, Morris RD, Morris MK, Krawiecki N. Risk factors associated with long term social and behavioural problems among children with brain tumours. J Psychosoc Oncol. 2003;21:73-87.

14. Barrera M, Schulte F. A group social skills intervention program for survivors of childhood brain tumours. J Pediatr Psychol. 2009;34(10):1108-18.

15. Poggi G, Liscio M, Pastore V, Adduci A, Galbiati S, Spreafico F, et al. Psychological intervention in young brain tumour survivors: the efficacy of the cognitive behavioural approach. Disabil Rehabil. 2009;31(13):1066-73.

16. Devine KA, Bukowski WM, Sahler OJ, Ohman-Strickland P, Smith TH, Lown EA, et al. Social competence in childhood brain tumour survivors: feasibility and preliminary outcomes of a peer-mediated intervention. J Dev Behav Paediatr. 2016:37:475-82.

17. Achenbach TM, Rescorla LA. Manual for the ASEBA school-age forms and profiles. Burlington: University of Vermont Research Centre for Children, Youth and Families; 2001.

18. Radcliffe J, Bennett D, Kazak AE, Foley B, Phillips PC. Adjustment in childhood brain tumour survival: child, mother, teacher report. J Paediatr Psychol. 1996;21(4):529-39.

19. Dessens $A B$, van Herwerden MC, Aarsen FK, Birnie E, Catsman-Berrevoets CE. Health-related quality of life and emotional problems in children surviving brain tumour treatment: a descriptive study of 2 cohorts. J Paediatr Hemato Oncol. 2016;33(5):282-94.

20. Fuemmeler BF, Mullins LL, Marx BP. Posttraumatic stress and general distress among parents of children surviving a brain tumour. J Child Health Care. 2001;30(3):169-82.

21. Stuber ML, Meeske KA, Krull KR, Leisenring W, Stratton K, Kazak AE, et al. Prevalance and predictors of posttraumatic stress disorder in adult survivors of childhood cancer: a report from the childhood cancer survivor study. Pediatrics. 2010;125(5):1124-36.

22. Amidei C, Kushner DS. Clinical implications of motor deficits related to brain tumours. Neuro Oncol Pract. 2015;2(4):179-84.

23. Piscione PJ, Bouffet E, Mabbott DJ, Shams I, Kulkarni AV. Physical functioning in pediatric survivors of childhood posterior fossa brain tumours. Neuro Oncol. 2014;16(1):147-55.

24. Ness KK, Morris EB, Nolan VG, Howell CR, Gilchrist LS, Stovall M, et al. Physical performance limitations among adult survivors of childhood brain tumours. Cancer. 2010;116(12):3034-44.

25. Poretti A, Grotzer MA, Ribi K, Schonle E, Boltshauser E. Outcome of craniopharyngioma in children: long term complications and quality of life. Dev Med Child Neurol. 2004;46(4):220-9.

26. Dolson EP, Conklin HM, Li C, Xiong X, Merchant TE. Predicting behavioral problems in craniophargyngioma survivors after conformal radiation therapy. Pediatr Blood Cancer. 2009;52(7):860-4.

27. Brinkman TM, Palmer SL, Chen S, Zhang H, Evankovich K, Swain MA, et al. Parent-reported social outcome after treatment for paediatric embryonal tumours: a prospective longitudinal study. J Clin Oncol. 2012;30(33):4134-40.

28. Aukema EJ, Last BF, Meeteren AYN, Grootenhuis MA. Explorative study on the aftercare of paediatric brain tumour survivors: a parents' perspective. Support Care Cancer. 2011;19:1637-16.

\section{Publisher's Note}

Springer Nature remains neutral with regard to jurisdictional claims in published maps and institutional affiliations.

\section{Ready to submit your research? Choose BMC and benefit from:}

- fast, convenient online submission

- thorough peer review by experienced researchers in your field

- rapid publication on acceptance

- support for research data, including large and complex data types

- gold Open Access which fosters wider collaboration and increased citations

- maximum visibility for your research: over $100 \mathrm{M}$ website views per year

At BMC, research is always in progress.

Learn more biomedcentral.com/submissions 